\title{
Investigation of the effects of animal and plant based milk on satiety and postprandial glucose levels
}

\section{Hilal HIZLI GÜLDEMIIR ${ }^{1}$, İlkim GÜNEY ${ }^{2}$, Duygu GÖKSU², Büşrahan SANCAK ${ }^{2}$, Havvagül PEKDEMİR²}

\section{Cite this article as:}

Hızlı Güldemir, H., Güney, İ., Göksu, D., Sancak, B., Pekdemir, H. (2022). Investigation of the effects of animal and plant based mil on satiety and postprandial glucose levels. Food and Health, 8(1), 57-67. https://doi.org/10.3153/FH22006

${ }^{1}$ Anadolu University, Faculty of Health Sciences, Department of Nutrition and Dietetics, Eskişehir, Turkey

${ }^{2}$ Graduate Student of Istanbul Medipol University, Faculty of Health Sciences, Department of Nutrition and Dietetics, Istanbul, Turkey

ORCID IDs of the authors: H.H.G. 0000-0002-3951-5023

İ.G. 0000-0002-9523-5034

D.G. 0000-0001-7390-4199

B.S. 0000-0002-2200-2184

H.P. 0000-0002-3160-5091

Submitted: 18.06 .2021

Revision requested: 30.08 .2021

Last revision received: 11.10 .2021

Accepted: 15.10 .2021

Published online: 23.12 .2021

Correspondence:

Hilal HIZLI GÜLDEMIR

E-mail:

hilalhizli@gmail.com

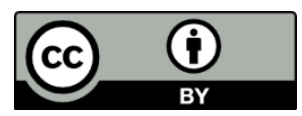

Available online at http://jfhs.scientificwebjournals.com

\begin{abstract}
The aim of this study was to determine the short-term effects of animal and plant-based milk consumption on postprandial glycemia, toughness, food intake of healthy individuals. Cow milk and soymilk were used as the test drink and commercial fruit juice as the control group. In the study in which 19 healthy adult subjects participated, fasting blood glucose and postprandial blood glucose analysed, visual analog scale and appetite were questioned. Then, 24-hour food comsumption records were taken and energy and macronutrients were calculated and compared. While the highest energy intake was on the day that cow milk was consumed, no significant relationship was found between test groups in terms of energy and macronutrient intake ( $p>0.05)$. It was determined that the difference between fasting and postprandial blood glucose was in the week in which the highest cow milk was consumed and this change was significant $(\mathrm{p}<0.05)$. It was thought that the satiety effect of cow milk may be higher than that of soy milk due to its animal protein and saturated fat content.
\end{abstract}

Keywords: Appetite, Blood glucose, Cow milk, Satiety, Soymilk 


\section{Introduction}

Animal milk is defined as the non-colostrum secretion produced by the mammary glands of healthy mammals to feed their young after birth and can be secreted from 15 days before to 5 days after birth (Godden, 2008). Milk consumption from domestic animals can be attributed to the seventh millennium BC in Northwest Anatolia (Evershed et al., 2008). Since then, consumption of milk and its use as a food ingredient, especially cow milk, have emerged and proliferated on every inhabited continent, playing an important role in the diet of people of all ages (Evershed et al., 2008; WijesinhaBettoni and Burlingame, 2013).

It is stated that milk and dairy products with a content rich in calcium play an important role in the protection of cardiovascular diseases, high blood pressure, osteoporosis, type 2 diabetes, stroke and colon cancer in adults, and in the healthy development of bones and teeth in childhood and adolescence periods. In the Turkish Dietary Guidelines (TDG), our national nutrition guideline, it is recommended to consume three servings of milk and dairy products daily for adult men and women aged 18-49 years (TDG, 2016). Global milk production is projected to increase by $23 \%$ compared to 2013 global production level for the year 2025 worldwide. Demand growth is expected to occur mainly in Africa, South Asia and East Asia (FAO, 2016). The global plant based milk market is expected to triple in 2025 with a growth rate of $12.5 \%$ and reach a market volume of 24.6 billion United States Dollar (USD). The largest share in this market is soy milk (Haas et al., 2019). In our country, according to the results of the most recent Turkey Nutrition and Health Survey (TNHS) (2017), the frequency of those who consume pasteurized milk as cow milk every day is $2.1 \%$, the frequency of those who consume ultra-high temperature (UHT) milk every day is $4.8 \%$, and the frequency of those who consume street milk every day is $3.7 \%$ (TNHS, 2019).

The definition of milk as an ingredient, beverage and nutrient source has come under scrutiny in recent years, as the presence of many different plant-based milk-like beverages on the market favors using the term "milk" to describe products formulated to mimic and replace cow milk. Cow milk has been studied recently due to its environmental effects and ethical considerations regarding animal welfare. In addition to ethical issues related to the use of animals, health problems such as dietary restrictions, allergies and lactose intolerance, and sustainability as a current issue have affected consumer demand for alternatives to cow milk (Sethi et al., 2016; Vanga and Raghavan, 2018). In line with this demand, the widely preferred options are plant-based milk substitutes, namely "plant-based milk". Plant-based milks are suspensions containing plant substitutes dissolved in water and fragmented plant material, and they resemble cow milk in appearance (Erk et al., 2019). The main varieties are plant milks such as soy, almond, rice and coconut milks, and less common hemp, hazelnut, macadamia nut, flax, oat and spelled (Vanga and Raghavan, 2018, Astolfi et al., 2020).

Plant-based milk alternatives are becoming increasingly popular, but most are nutritionally unbalanced compared to cow milk. However, milk alternatives contain bioactive components that have health-promoting properties and appeal to conscious consumers. Therefore, their ingredients and effects need to be carefully evaluated, as they can significantly affect human health (Liu, 2004; Sethi et al., 2016).

Production of animal dairy products has a significant environmental impact. The main environmental problems associated with milk production are soil degradation, air and water pollution, and biodiversity loss (Haas et al., 2019). Plantbased milks are often presented as a healthy, sustainable and animal welfare-friendly alternative (Clayton, 2021). According to Chapman's research, when the environmental impact of each milk type is examined, the results show that the carbon emission of cow milk per $200 \mathrm{~mL}$ is $0.63 \mathrm{~kg}$, the land use is $1.79 \mathrm{~m}^{2}$ and the water consumption is 125.6 liters, while the carbon emission for soy milk is $0.2 \mathrm{~kg}$, land use is 0.13 $\mathrm{m}^{2}$ and water consumption and has been shown to be 5.6 liters (Chapman, 2021).

The great interest of nutritionists in soy milk is due to the fact that it has a well-proportioned amino acid pattern compared to other vegetable proteins and is an alternative to cow milk. Soy milk has a nutritional composition comparable to cow milk. Compared to the compositions of cow milk, soy milk composition contains higher vegetable protein, iron, unsaturated fatty acids and niacin, while the amounts of fat, carbohydrates and calcium are lower. Its main advantage is that it does not contain cholesterol and lactose and contains 0.25 $\mathrm{mg} / \mathrm{g}$ total isoflavones on wet weight (Gursoy et al., 1999).

Due to the high protein content and fatty acid composition of cow milk, satiety effects have been investigated and these studies show that consumption of cow milk products can increase satiety (Onvani et al., 2017). One mechanism explaining the effect on satiety of dairy products concluded that, given its rapid digestion and absorption, it is related to whey protein resulting in increased plasma concentration of gut hormones and total plasma amino acids (Anderson and Moore, 2004; Boirie et al., 1997). Milk proteins are thought to increase satiety and suppress short-term food intake com- 
pared to other sources, but the effect of milk proteins or casein is still unclear (Paddon-Jones et al., 2008). Whey protein has been shown to suppress hunger more potently, resulting in lower food intake compared to casein (Hall et al., 2003). Therefore, the aim of this study is to investigate the effect of consumption of animal and plant dairy products (cow milk and soy milk) on satiety and postprandial blood glucose.

\section{Materials and Methods}

\section{Research Location, Time and Sample Selection}

The research was carried out in three consecutive weeks, on the same days and times each week, between April 10 and June 7, 2019. The research sample consists of 19 healthy female individuals aged between 18-25 years, without any acute or chronic disease and not using chronic medication, with a normal body mass index (BMI) range, without allergy or intolerance to cow milk and soymilk. Ethical approval (number: 10840098-604.01.01-E.14958, date: 06.05.2019) from Istanbul Medipol University Non-Interventional Clinical Research Ethics Committee and written consent form were obtained from the participants.

\section{General Plan of the Study}

A total of 19 female were included in this study. The experiment process lasted about three hours and was carried out at one-week intervals. The same individuals participated in all three experimental groups and came to the experiment site after at least eight hours of overnight fasting. During the experiment, in the laboratories of Istanbul Medipol University, individuals sat and waited in the laboratory, and light activities such as reading books were allowed.

First, a questionnaire form containing general and demographic information and evaluating milk consumption habits were filled, then fasting blood glucose levels were measured and visual analog scale (VAS) was recorded. Afterwards, the first meal, the test breakfast, was presented. All of the test meals were consumed within 15 minutes. Subsequently, visual analog scale (VAS) responses were recorded every half hour and blood glucose levels were measured at 120 minutes after the first bite. The next day, the 24-hour food consumption record was taken by the researchers by calling the individuals by phone. The research flowchart is summarized in Table 1.

\section{Energy and Macro Nutrient Content of Drinks and Test Meal Given During the Experiment}

For the test meal, breakfast, a sandwich consisting of two thin slices of whole wheat bread (50 g) with tomato, cucumber and lettuce and a test drink were served. The test drink was given on the same day and at the same time each week, along with the sandwich for three consecutive weeks, respectively, cow milk $(200 \mathrm{~mL})$ in the first week, soymilk $(200 \mathrm{~mL})$ in the second week, and mixed aroma containg fruit juice as commercially prepared with no added sugar $(200 \mathrm{~mL})$ as the control group in the last week. Participants were informed about the content of the meal they would consume. Carbohydrate, protein and fat contents of three different breakfast test meals are given in Table 2 .

Table 1. Research Flow Chart

\begin{tabular}{ll}
\hline Hour & Intervention \\
\hline $\mathbf{0 9 : 0 0}$ & $\begin{array}{l}\text { Filling out a questionnaire evaluating the voluntary consent form, general and } \\
\text { demographic information and milk consumption habits and determining the } \\
\text { fasting blood glucose of the individuals. }\end{array}$ \\
$\mathbf{0 9 : 1 5 - 0 9 : 3 0}$ & VAS application and test meal consumed within 15 minutes \\
$\mathbf{1 0 : 0 0}$ & VAS application \\
$\mathbf{1 0 : 3 0}$ & VAS application \\
$\mathbf{1 1 : 0 0}$ & VAS application \\
$\mathbf{1 1 : 3 0}$ & VAS application and 2nd hour postprandial blood glucose determination \\
Next Day 12.00 & Obtaining a daily food consumption record \\
\hline
\end{tabular}


Table 2. Energy and macronutrient content of test meals

\begin{tabular}{lcccc}
\hline Groups & Energy (kcal) & Carbohydrate (g) & Protein(g) & Fat (g) \\
\hline Cow Milk + Sandwich & 232.8 & 31.44 & 10.6 & 6.9 \\
\hline Soy Milk + Sandwich & 200.4 & 31.2 & 7 & 4.9 \\
\hline Juice + Sandwich & 214.4 & 35.6 & 4.6 & 0.9 \\
\hline
\end{tabular}

\section{Data Evaluation}

The demographic information of the participants was collected by answering the questions in the given questionnaire, and body mass index (BMI) values were calculated by the researchers. Blood glucose level was measured by glucometer (Accu Check, USA) in the second blood drop taken from the first capillary blood from the fingertip.

In this study, the visual analog scale (VAS) applied evaluate the hunger, satiety, desire to eat and the amount they can eat. The visual analog scale is a scale made by looking at food requests according to appetite, satiety and taste. Classifications are determined by selecting the appropriate point from both ends with a horizontal line of ten $\mathrm{mm}$. The measure in millimeters from the last point of the line to the marked place was determined as VAS (Wewers and Lowe, 1990).

On the next day after the experiment, 24-hour food consumption was recorded by the researcher using the retrospective method. Energy and macronutrient consumption of individuals were calculated with the Nutrition Information System (BeBiS) program (BeBiS, 2004).

\section{Statistical Analysis}

SPSS 22.0 statistical package program was used for the statistical evaluation of the data. Data obtained from individuals are expressed as arithmetic mean $(\bar{x})$, standard deviation (S), number and percentage (\%). The change between fasting and postprandial blood glucose obtained from individuals was evaluated using the Wilcoxon T test. VAS scores by weeks and the change between total energy and macronutrient intakes were evaluated using the Friedman test. In statistical analysis, the significance value within and between groups was taken as $\mathrm{p}<0.05$.

\section{Results and Discussion}

According to the results of the visual analog scale, at the end of the two-hour period following the consumption of the test meal, it was determined that the lowest hunger, desire to eat and amount to eat scores and the highest satiety score were in the cow milk group (Table 3). It was found that these values for hunger and desire to eat significantly different at the end of the two-hour period $(\mathrm{p}<0.05)$. Changes in satiety status also showed a significant difference between cow milk and other groups during the process $(\mathrm{p}<0.05)$. Visual analog scale (VAS) applied at five different times in each application at 0 , $30,60,90$ and 120 minutes in order to understand how the appetite parameters of individuals change depending on time, shown in Table 3. Results can be shown in Figure 1-4. A review was published by Bendtsen et al in 2013 to examine the evidence from controlled clinical studies investigating the effects of milk protein consumption and other protein sources on appetite regulation, energy expenditure and body weight. According to this review, it has been observed that cow milk protein is beneficial in increasing and maintaining weight loss due to its effects on appetite regulation and energy expenditure and whey protein, one of the milk proteins, has a more satisfying effect in the short term and casein in the long term (Bendtsen et al., 2013). According to a meta-analysis by Onvani et al. in which 3617 human clinical studies of milk and dairy products were reviewed and the effects on satiety and food intake were examined in seven studies involving 237 participants, it was stated that there was a significant decrease in hunger and there was a significant difference between study heterogeneity. In subgroup analyzes based on intervention dose, it was found that consumption of more than 500 $\mathrm{ml} /$ day dairy products significantly reduced hunger. It is said to be associated with an insignificant reduction in dairy consumption of less than $500 \mathrm{ml}$ (Onvani et al., 2017). In a study by Alfenas et al. conducted on appetite and energy metabolism of different protein types in Brazil in 2009, a control group formed using whey protein, casein protein, soy protein and a comparison between them. As a result, casein protein offers a stronger satiety power than whey protein, due to its high dietary thermogenesis. It is stated that soy protein also can have a significant effect on postprandial energy expenditure compared to whey protein and control. It is highlighted that whey protein consumption can be effective on body weight and body fat control (Alfenas et al., 2010). In this study, the lowest average visual analog scale score applied every half hour determined that, the feeling of desire to eat 
was less when the individuals consumed cow milk. It was assumed that two studies point to similar results. This can be explained by the animal-derived protein and saturated fat content of cow's milk.

\section{Hunger Status}

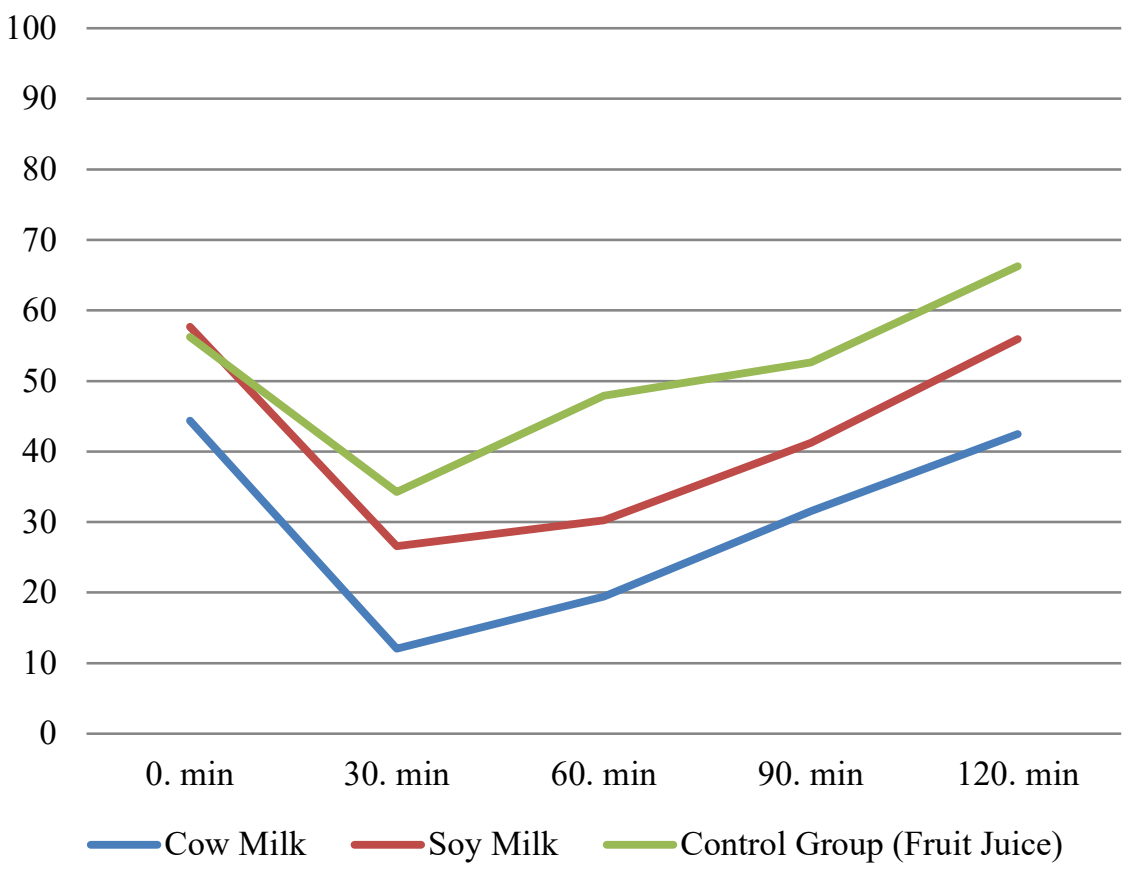

Figure 1. Time-dependent change of individual hunger scores

\section{Satiety Status}

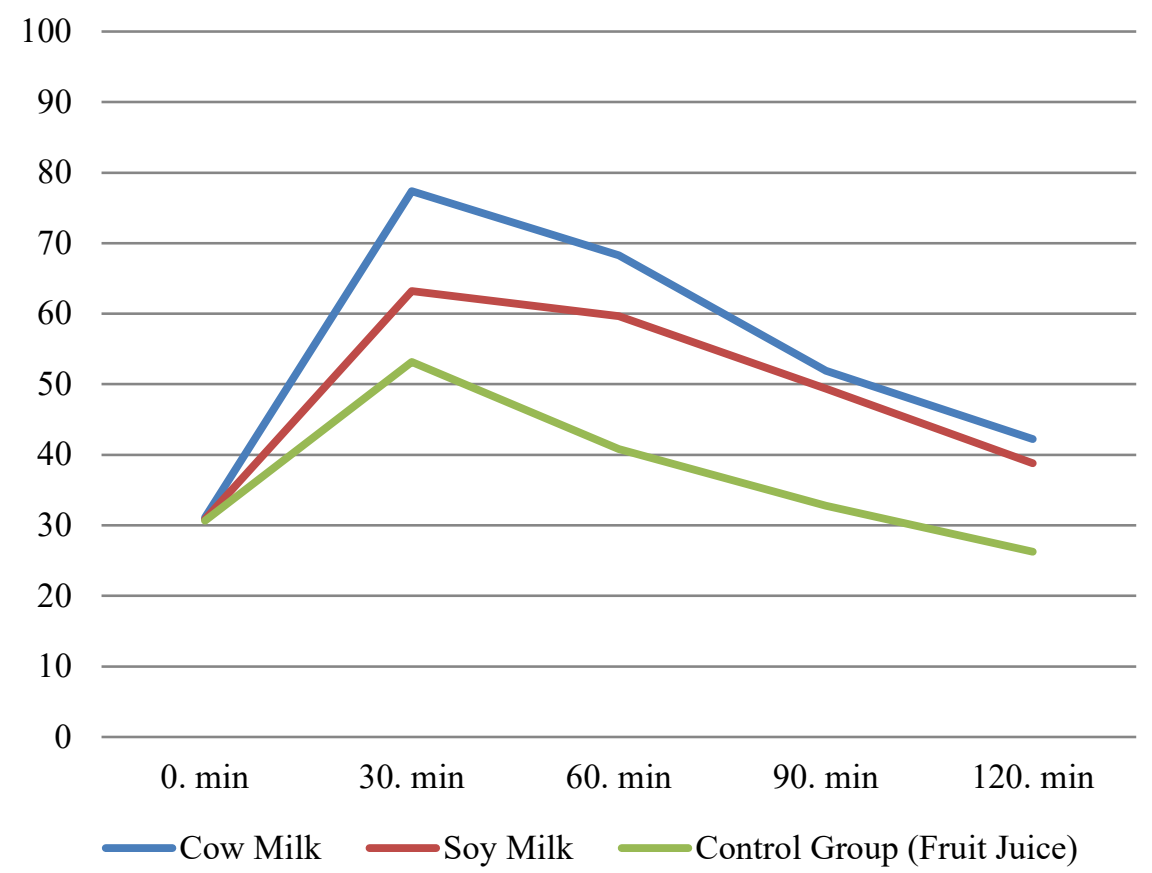

Figure 2. Time-dependent change of individual satiety scores 


\section{Eating Desire}

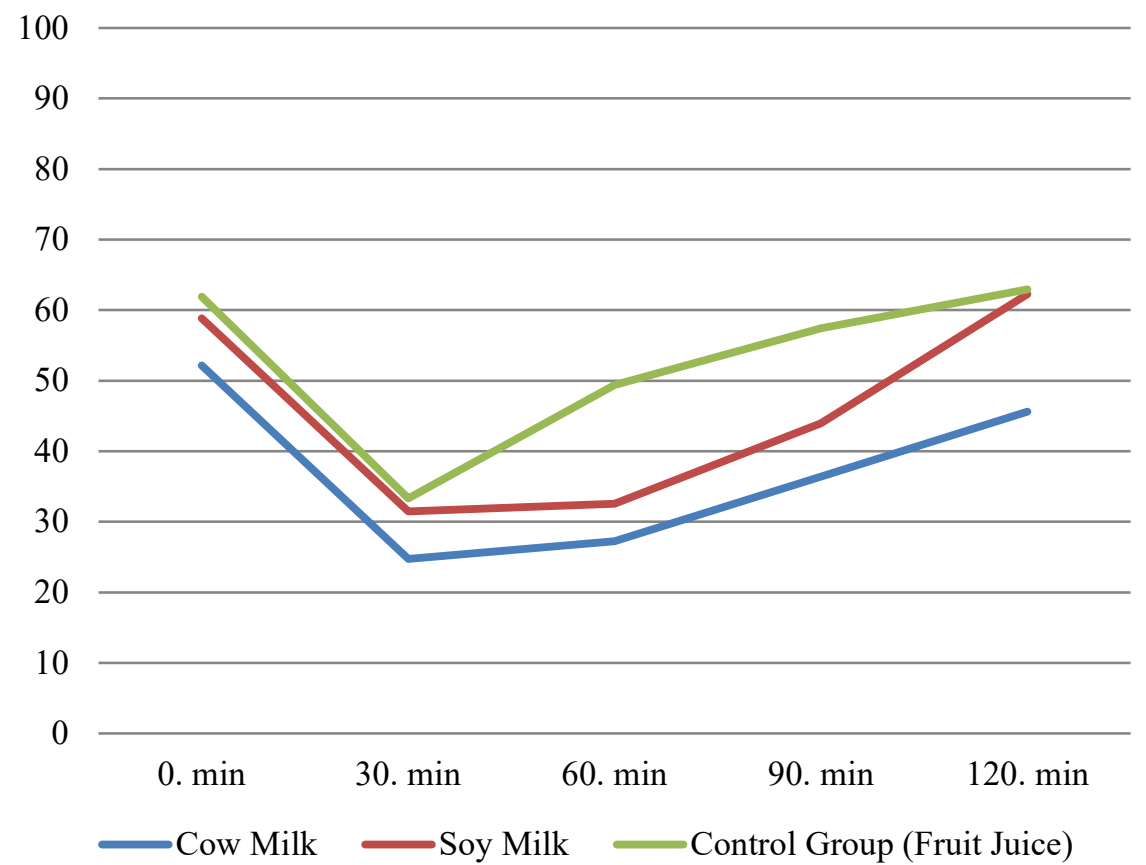

Figure 3. Time-dependent change of individual eating desire scores

The Amount That An Individual Can Eat

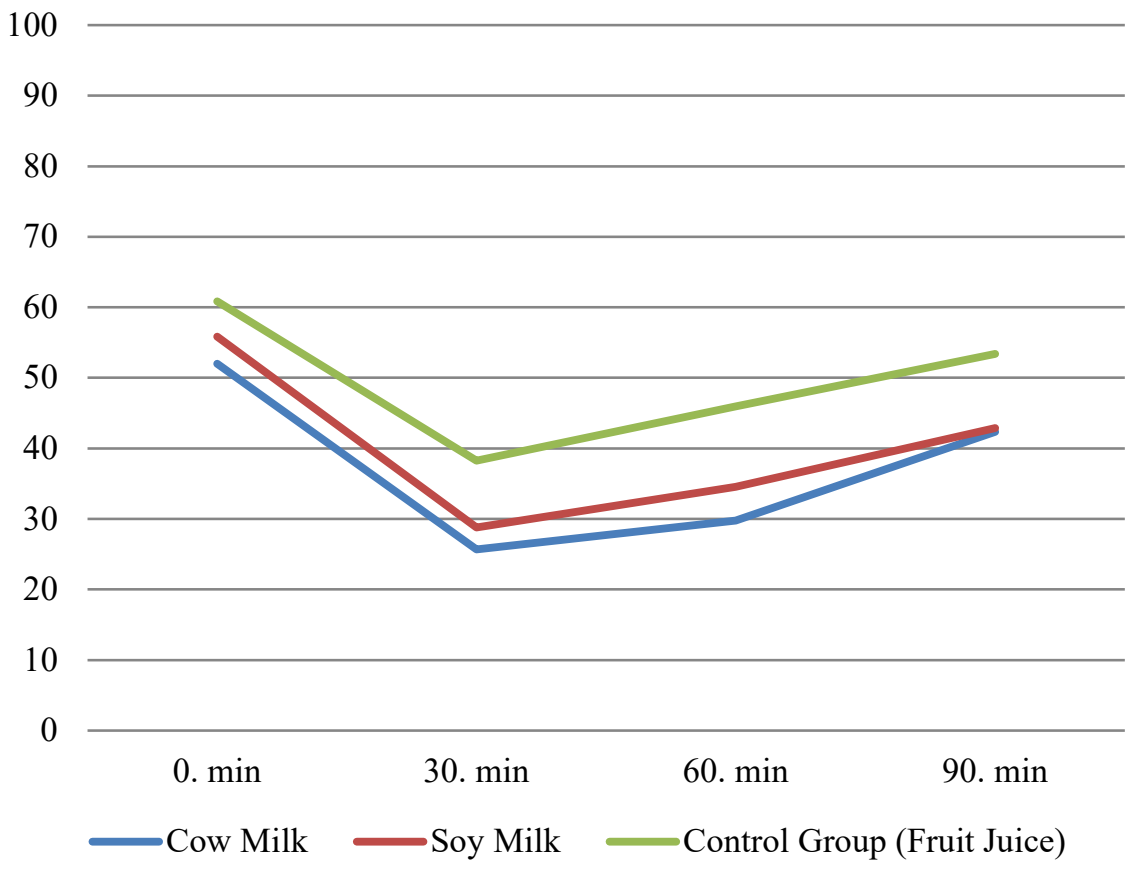

Figure 4. Time-dependent change of the amount that an individual can eat scores 
Table 3. Visual analog scale scores

\section{Cow Milk}

\section{Hunger Status}

\begin{tabular}{|c|c|c|c|c|}
\hline 09.30 & $44.37 \pm 26.97$ & $57.68 \pm 30.88$ & $56.21 \pm 29.98$ & 0.094 \\
\hline 10.00 & $12.05 \pm 13.74$ & $26.58 \pm 22.25$ & $34.26 \pm 24.87$ & 0.001 \\
\hline 10.30 & $19.42 \pm 20.40$ & $30.26 \pm 24.21$ & $47.89 \pm 24.55$ & 0.001 \\
\hline 11.00 & $31.53 \pm 25.18$ & $41.21 \pm 22.36$ & $52.63 \pm 24.21$ & 0.170 \\
\hline 11.30 & $42.47 \pm 28.02$ & $55.95 \pm 24.75$ & $66.26 \pm 25.17$ & 0.001 \\
\hline \multicolumn{5}{|c|}{ Satiety Status } \\
\hline 09.30 & $31.11 \pm 26.44$ & $30.84 \pm 24.97$ & $30.63 \pm 24.72$ & 0.841 \\
\hline 10.00 & $77.37 \pm 15.24$ & $63.21 \pm 22.78$ & $53.16 \pm 27.00$ & 0.001 \\
\hline 10.30 & $68.26 \pm 20.16$ & $59.68 \pm 25.37$ & $40.79 \pm 26.15$ & 0.001 \\
\hline 11.00 & $51.89 \pm 23.11$ & $49.36 \pm 24.73$ & $32.79 \pm 18.44$ & 0.033 \\
\hline 11.30 & $42.21 \pm 25.89$ & $38.79 \pm 25.20$ & $26.26 \pm 18.37$ & 0.065 \\
\hline \multicolumn{5}{|c|}{ Eating Desire } \\
\hline 09.30 & $52.16 \pm 19.59$ & $58.84 \pm 28.51$ & $61.89 \pm 23.68$ & 0.029 \\
\hline 10.00 & $24.74 \pm 18.26$ & $31.47 \pm 24.05$ & $33.32 \pm 23.16$ & 0.201 \\
\hline 10.30 & $27.26 \pm 19.66$ & $32.53 \pm 23.25$ & $49.37 \pm 22.06$ & 0.016 \\
\hline 11.00 & $36.42 \pm 19.33$ & $43.95 \pm 20.93$ & $57.42 \pm 22.98$ & 0.040 \\
\hline 11.30 & $45.63 \pm 21.79$ & $62.26 \pm 18.58$ & $62.95 \pm 22.41$ & 0.003 \\
\hline \multicolumn{5}{|c|}{ The Amount That an Individual Can Eat } \\
\hline 09.30 & $52.00 \pm 15.38$ & $55.84 \pm 26.23$ & $60.84 \pm 23.05$ & 0.564 \\
\hline 10.00 & $25.68 \pm 19.01$ & $28.79 \pm 22.74$ & $38.26 \pm 24.84$ & 0.128 \\
\hline 10.30 & $29.79 \pm 20.82$ & $34.58 \pm 23.26$ & $45.95 \pm 24.62$ & 0.008 \\
\hline 11.00 & $42.32 \pm 23.36$ & $42.89 \pm 21.50$ & $53.37 \pm 21.84$ & 0.175 \\
\hline 11.30 & $48.68 \pm 24.13$ & $57.53 \pm 16.87$ & $62.11 \pm 21.70$ & 0.075 \\
\hline
\end{tabular}

Values are given as mean \pm standard deviation. $p<0.05$ was considered significant. Visual analog scale form is determined as linear line length $\mathrm{mm}$.

Soy Milk

Fruit Juice

p 
The total energy intake and percentages of carbohydrate, protein and fat of the 24-hour food consumption records of the individuals according to the groups are shown in Table 4. It was found that the average daily energy intake of the individuals participating in the study was $1872.26 \pm 520.97 \mathrm{kcal}$ on the day they consumed cow milk as a test drink, $1721 \pm 598.47$ $\mathrm{kcal}$ on the day they consumed soymilk, and $1702.42 \pm 345.42$ $\mathrm{kcal}$ on the day they consumed fruit juice. There is no significant difference between the average daily energy intakes according to the groups $(\mathrm{p}>0.05)$. In a study conducted with individuals with low $(<1$ portion / day) or high $(>3$ portions / day) milk consumption in which the effects of dairy consumption on food intake and appetite were investigated. Consuming three portions of dairy products every day contributes significantly to energy intake. It was observed that the increase in energy intake was higher in men than in women and that increased intake of dairy products did not cause a change in feelings of satiety enough to compensate for the additional calories taken (Hollis and Mattes, 2012). Considering the 24hour food consumption records of the individuals in the study group, the highest total energy intake is the week of cow milk consumption as the test drink, and the lowest is the week of fruit juice consumption. The reason for the difference from other studies in the literature may be related to the change in food consumption of individuals within 24 hours according to various environmental and sensory stimuli.

Fasting and postprandial blood glucose levels of the individuals are given in Table 5. The postprandial blood glucose levels of the individuals participating in the study were found as $103.42 \pm 11.59 \mathrm{mg} / \mathrm{dl}$ in the week that cow milk was consumed, $97.84 \pm 11.15 \mathrm{mg} / \mathrm{dl}$ in the week that soymilk was consumed, and $95.47 \pm 9.82 \mathrm{mg} / \mathrm{dl}$ in the week fruit juice consumed. It was determined that the change between fasting and postprandial blood glucose for the week in which only cow milk was consumed as a test drink was significant $(p<0.05)$. In a study published in 2011 in Greece by Vallianou et al. on the effects of high blood glucose levels on hypertensive individuals' consumption of full-fat dairy products, 490 volunteers were included in the study. Multiple linear regression models were applied to determine the effect of full-fat dairy consumption on blood glucose levels considering age, gender and BMI factors. As a result, it was found that full-fat dairy products are associated with higher blood glucose levels; however, they stated that the relationship between dairy groups did not show any significance (Vallianou et al., 2011). On the other hand, a study published in 2014 stated that lowfat dairy products increase fasting blood glucose more than full-fat dairy products (Anekwe and Rahkovsky, 2014). A study conducted on thirty healthy individuals in 2017 compared the effect of dairy products and a non-dairy beverage, consumed together with carbohydrates on subjective appetite, food intake and postprandial glycemia in healthy elderly adults. Between the groups of soy drink, $2 \%$ cow milk, cheese, yoghurt and the control group showed that there is no difference in terms of nutritional intake (Law et al., 2017). When compared with this study, it is seen that postprandial blood glucose is in cow milk group as the highest, and the difference between satiety and hunger levels is also the highest in the same group. The reason for this is thought that cow milk has more carbohydrate and fat than soymilk, as well as protein content of animal origin. However, the reason why the other results are not meaningful may be that they are carried out for a short time with a small number of people.

Table 4. 24-hour energy and macronutrient intake of individuals after the experiment

\begin{tabular}{llcccc}
\hline & Total Energy (kcal) & CHO \% & Protein \% & Fat \% & p* \\
\cline { 1 - 5 } Cow Milk & $1872.26 \pm 520.97$ & $46.47 \pm 5.28$ & $14.31 \pm 2.56$ & $39.26 \pm 4.60$ & \\
\cline { 1 - 4 } Soy Milk & $1721.00 \pm 598.47$ & $52.26 \pm 7.55$ & $15.31 \pm 3.35$ & $32.42 \pm 7.08$ & \multirow{2}{*}{0.274} \\
\cline { 1 - 4 } Fruit Juice & $1702.42 \pm 345.42$ & $45.47 \pm 6.04$ & $14.94 \pm 2.43$ & $39.89 \pm 7.37$ &
\end{tabular}

\footnotetext{
* $\mathrm{p}$ value for total energy, Friedman test. Values are given as mean \pm standard deviation. $\mathrm{p}<0.05$ was considered significant. CHO: Carbohydrate
} 
Table 5. Fasting and postprandial blood glucose levels of individuals

\begin{tabular}{cccr}
\hline & Fasting Blood Glucose Level (mg/dL) & Postprandial Blood Glucose Level (mg/dL) & p \\
\hline Cow Milk & $86.21 \pm 7.26$ & $103.42 \pm 11.59$ & $\mathbf{0 . 0 1 2}$ \\
\hline Soy Milk & $87.68 \pm 9.40$ & $97.84 \pm 11.15$ & 0.731 \\
\hline Juice & $88.15 \pm 8.14$ & $95.47 \pm 9.82$ & 0.277 \\
\hline
\end{tabular}

Values are given as mean \pm standard deviation. $\mathrm{p}<0.05$ was considered significant. Fasting and postprandial blood glucose was determined in $\mathrm{mg} / \mathrm{dl}$ by glucometer.

Some of the limitations of this study are that participants have information about the content of meals consumed without blinding, and that blood glucose levels were measured with a glucometer, not with venous blood.

\section{Conclusion}

As a result of the study conducted to investigate the effects of animal and plant-based milk on satiety, and postprandial glucose levels; cow milk was found to cause higher feelings of satiety and higher blood glucose levels after two hours compared to soy milk and fruit juice as a control group. It is thought that long term and more studies are needed on the effects of various animal and plant-based milks on short-term satiety, food intake, hunger and satiety.

\section{Compliance with Ethical Standard}

Conflict of interests: The author declares that for this article they have no actual, potential or perceived conflict of interests.

Ethics committee approval: Ethical approval (number: 10840098604.01.01-E.14958, date: 06.05.2019) from Istanbul Medipol University Non-Interventional Clinical Research Ethics Committee and written consent form were obtained from the participants.

Funding disclosure: -

Acknowledgments: -

Disclosure: -

\section{References}

Alfenas R.C., Bressan, J, Paiva, A.C. (2010). Effects of protein quality on appetite and energy metabolism in normal weight subjects. Arquivos Brasileiros de Endocrinologia \& Metabologia, 54(1), 45-51.

https://doi.org/10.1590/S0004-27302010000100008
Anekwe, T.D., Rahkovsky, I. (2014). The association between food prices and the blood glucose level of US adults with type 2 diabetes. American Journal of Public Health, 104(4), 678-685.

https://doi.org/10.2105/AJPH.2013.301661

Anderson, G.H., Moore, S.E. (2004). Dietary proteins in the regulation of food intake and body weight in humans. The Journal of Nutrition, 134(4), 974-979.

https://doi.org/10.1093/jn/134.4.974S

Astolfi, M.L., Marconi, E., Pronato C., Canepari S. (2020). Comparative elemental analysis of dairy milk and plant-based milk alternatives. Food Control, 116, 107327. https://doi.org/10.1016/j.foodcont.2020.107327

Bendtsen, L.Q., Lorenzen, J.K., Bendsen, N.T., Rasmussen, C., Astrup, A. (2013). Effect of dairy proteins on appetite, energy expenditure, body weight, and composition: a review of the evidence from controlled clinical trials. $A d$ vances in Nutrition, 4(4), 418-438.

https://doi.org/10.3945/an.113.003723

BeBis Nutrition Data Base Software Data Base. The German Food Code and Nutrient Data Base (BLSII.3, 1999) with additions from USDA-sr and other sources, Turkey, Istanbul, 2004.

Boirie, Y., Dangin, M., Gachon, P., Vasson, M.P., Maubois, J.L., Beaufrère, B. (1997). Slow and fast dietary proteins differently modulate postprandial protein accretion. Proceedings of the National Academy of Sciences, 94 (26), 14930-14935.

https://doi.org/10.1073/pnas.94.26.14930

Chapman, L. (2021). Which vegan milk is best for the environment? Retrieved from https://www.sciencefocus.com/science/which-vegan-milk-is-best-for-the-environment (accessed 19.05.2021). 
Clayton, A. (2020). Milk. Retrieved from https://www.ethicalconsumer.org/food-drink/shopping-guide/milk (accessed 19.05.2021).

Erk, G., Seven, A., Akpınar, A. (2019). Vegan ve vejetaryan beslenmede probiyotik bitkisel bazlı süt ürünlerinin yeri. Glda, 44 (3), 453-462.

https://doi.org/10.15237/gida.GD18083

Evershed, R.P., Payne, S., Sherratt, A.G., Copley, M.S., Coolidge, J., Urem-Kotsu, D., Kotsakis, K., Özdoğan, M., Özdoğan, A.E., Nieuwenhuyse, O., Akkermans, P.M.M.G., Bailey, D., Andeescu, R.R., Campbell, S., Farid, S., Hodder, I., Yalman, N., Özbaşaran, M., Bıçakçı, E., Garfinkel, Y., Levy, T., Burton, M.M. (2008). Earliest date for milk use in the Near East and southeastern Europe linked to cattle herding. Nature, 455, 528-531.

https://doi.org/10.1038/nature07180

Food and Agricultural Organization (FAO). (2016). Dairy Sector Global Facts. Retrieved from https://fil-idf.org/wpcontent/uploads/2016/12/FAO-Global-Facts-1.pdf (accessed on 11 May 2021).

Gursoy, O., Gokçe R., Kınık Ö. (1999). Beslenmede yeni yaklaşımlar: Soya sütü ve ürünleri. Mühendislik Bilimleri Dergisi, 5 (2-3), 1123-1130.

Godden, S. (2008). Colostrum management for dairy calves. Veterinary Clinics of North America: Food Animal Practice, 24, 19-39.

https://doi.org/10.1016/j.cvfa.2007.10.005

Hall, W.L., Millward, D.J., Long, S.J., Morgan, L.M. (2003). Casein and whey exert different effects on plasma amino acid profiles, gastrointestinal hormone secretion and appetite. British Journal of Nutrition, 89(2), 239-248.

https://doi.org/10.1079/BJN2002760

Haas, R., Schnepps, A., Pichler, A., Meixner, O. (2019). Cow milk versus plant-based milk substitutes: A comparison of product image and motivational structure of consumption. Sustainability, 11, 5046.

https://doi.org/10.3390/su11185046

Hollis, J., Mattes, R. (2012). Effect of increased dairy consumption on appetitive ratings and food intake. North American Association for the Study of Obesity, 15-6, 1520-1526. https://doi.org/10.1038/oby.2007.180
Law, M., Lee, Y.T., Vien, S., Luhovyy, B.L., Anderson, G.H. (2017). The effect of dairy products consumed with high glycemic carbohydrate on subjective appetite, food intake, and postprandial glycemia in older adults. Applied Physiology, Nutrition, and Metabolism, 42(11), 1210-1216.

https://doi.org/10.1139/apnm-2017-0210

Liu, K. (2004). Soybean as Functional Foods and Ingredients. Champaign, IL, USA: AOCS Press. ISBN 1-893997-332.

Onvani, S., Haghighatdoos, F., Surkan, P. J., Azadbakht, L. (2017). Dairy products, satiety and food intake: A metaanalysis of clinical trials. Clinical Nutrition, 36, 389-398.

https://doi.org/10.1016/j.clnu.2016.01.017

Paddon-Jones, D., Westman, E., Mattes, R. D., Wolfe, R. R., Astrup, A., Westerterp-Plantenga, M. (2008). Protein, weight management and satiety. The American Journal of Clinical Nutrition, 87(5), 1558-1561.

https://doi.org/10.1093/ajcn/87.5.1558S

Sethi, S., Tyagi, S. K., Anurag, R. K. (2016). Plant-based milk alternatives an emerging segment of functional beverages: A review. Journal of Food Science \& Technology, 53, 3408-3423.

https://doi.org/10.1007/s13197-016-2328-3

Turkish Dietary Guideline (TDG) (2015). T.C. Ministry of Health Publication No: 1031, Ankara 2016. Retrieved from https://dosyasb.saglik.gov.tr/Eklenti/10915,tuber-turkiye-

beslenme-rehberipdf.pdf (accessed 17.05.2021).

Turkish Nutrition and Health Survey (TNHS) (2017). T.C. Ministry of Health Publication No: 1132, Ankara 2019. Retrieved from

https:/hsgm.saglik.gov.tr/depo/birimler/saglikli-beslenmehareketli-hayat-db/Yayinlar/kitaplar/TBSA_RAPOR KITAP 20.08.pdf (accessed 17.05.2021).

Vallianou, N., Bountziouka, V., Evangelopoulos, A., Bonou, M., Katsagoni, C., Barbetseas, J. (2011). High full fat dairy products intake is associated with increased blood glucose levels among hypertensive people. Atherosclerosis Supplements, 12(1), 13-184.

https://doi.org/10.1016/S1567-5688(11)70693-6

Vanga, S.K., Raghavan, V. (2018). How well do plantbased alternatives fare nutritionally compared to cow's milk? Journal of Food Science\& Technology, 55, 10-20.

https://doi.org/10.1007/s13197-017-2915-y 
Wewers M.E., Lowe N.K. (1990). A critical review of visual analogue scales in the measurement of clinical phenomena. Research in Nursing and Health, 13, 227-236.

https://doi.org/10.1002/nur.4770130405

Wijesinha-Bettoni, R., Burlingame, B. (2013). Milk and dairy product composition. In E. Muehlhoff, A. Bennett, \& D. McMahon (Eds.), Milk and dairy products in human nutrition (pp. 41e90). Rome, Italy: Food and Agriculture Organisation (FAO).
World Health Organization (WHO) (2016). World Health Day: WHO calls for global action to health rise in and improve care for people with diabetes. Retrieved from https://www.who.int/news/item/06-04-2016-world-healthday-2016-who-calls-for-global-action-to-halt-rise-in-andimprove-care-for-people-with-diabetes (accessed on 2 May 2021). 